\title{
Intimate Partner Violence and HIV Among Drug- Involved Women: Contexts Linking These Two Epidemics-Challenges and Implications for Prevention and Treatment
}

\author{
Nabila El-Bassel, Louisa Gilbert, Susan Witte, Elwin Wu \& Mingway Chang
}

To cite this article: Nabila El-Bassel, Louisa Gilbert, Susan Witte, Elwin Wu \& Mingway Chang (2011) Intimate Partner Violence and HIV Among Drug-Involved Women: Contexts Linking These Two Epidemics-Challenges and Implications for Prevention and Treatment, Substance Use \& Misuse, 46:2-3, 295-306, DOI: 10.3109/10826084.2011.523296

To link to this article: https://doi.org/10.3109/10826084.2011.523296

Published online: 08 Feb 2011.

Submit your article to this journal ¿

Џلll Article views: 292

Q View related articles $\square$

7 Citing articles: 53 View citing articles $₫$ 


\title{
Intimate Partner Violence and HIV Among Drug-Involved Women: Contexts Linking These Two Epidemics-Challenges and Implications for Prevention and Treatment
}

\author{
Nabila El-Bassel, Louisa Gilbert, Susan Witte, Elwin Wu and Mingway Chang \\ Social Intervention Group, School of Social Work, Columbia University, New York, New York, USA
}

Intimate partner violence (IPV) and HIV are two serious overlapping public health epidemics that disproportionately affect drug-involved women. This article reviews research that has identified a number of contexts that may explain the links between IPV and HIV transmission risks. These contexts include sexual coercion, fear of violence, negotiation of condom use, extradyadic relationships, disclosure of sexually transmitted infections or HIV seropositivity to intimate partners, drug involvement of women and their male partners, low social status of drug-involved women, relationship dependencies, and sex ratio imbalances. The article focuses on how the bidirectional relationship between IPV and HIV risks may be mediated by a history of childhood sexual abuse and post-traumatic stress disorder. Also addressed are the challenges that substance user treatment programs face in dealing with female clients who experience IPV and the implications for HIV prevention.

Keywords HIV, partner violence, drug-involved women, risk
factors

\section{INTRODUCTION}

Intimate partner violence (IPV) has been identified as a significant public health problem reaching epidemic proportions in the United States and affecting women from all walks of life, especially those who are drug-involved (Amaro, 1995; Amaro, Fried, Cabral, \& Zuckerman, 1990; Cunningham, Stiffman, Dore, \& Earls, 1994; El-Bassel, Gilbert, \& Rajah, 2003; El-Bassel, Gilbert,
Rajah, Foleno, \& Frye, 2000; Fernandez, 1995; Fontdevila, El-Bassel, \& Gilbert, 2005; Gilbert, ElBassel, Schilling, Wada, \& Bennet, 2000; Wingood \& DiClemente, 1997; Worth, 1989; Wyatt, 1991). Studies among women in substance user treatment ${ }^{1}$ have shown that past-year prevalence rates of physical and sexual IPV have ranged between 25\% and 57\% (El-Bassel et al., 2003; El-Bassel, Gilbert, Rajah, Foleno, \& Frye, 2001; ElBassel, Gilbert, Wu, Go, \& Hill, 2005a; Fontdevila et al., 2005; Gilbert, El-Bassel, Schilling, et al., 2000), which are three to five times higher than the rate range of $8 \%-16 \%$ found in epidemiological surveys of community-based samples of women (Caetano, Nelson, \& Cunradi, 2001; Straus \& Gelles, 1990; Tjaden \& Thoennes, 1998).

In several studies conducted in New York City by the authors of this article, prevalence rates of IPV were found to be high among drug-involved women as well as among a random sample of men in methadone treatment who were asked to report about perpetrating IPV against their female partners (El-Bassel, Gilbert, Wu, Chang, \& Fontdevila, 2007; El-Bassel et al., 2005a). In a recent study among a random sample of 416 sexually active women recruited from 11 methadone treatment programs in New York City, we found that $88 \%$ of the women reported physical and sexual IPV in their lifetime. Almost three quarters of the women in this sample (73\%) indicated that they experienced severe physical or sexual IPV. About one half (47\%) reported experiencing physical or sexual IPV in the past 6 months, and about one fifth (19\%) indicated that the physical or sexual IPV that they experienced in the past 6 months was severe (El-Bassel et al., 2005a).

\footnotetext{
${ }^{1}$ Treatment can be briefly and usefully defined as a planned, goal-directed, temporally structured change process, of necessary quality, appropriateness and conditions (endogenous and exogenous), which is bounded (by culture, place, time, etc.) and can be categorized into professional-based, tradition-based, mutual-help-based (such as Alcoholics Anonymous and Narcotics Anonymous), and self-help ("natural recovery") models. There are no unique models or techniques used with substance users-of whatever types and heterogeneities-that are not also used with nonsubstance users. In the West, with the relatively new ideology of "harm reduction" and the even newer quality-of-life treatment-driven model, there are now a new set of goals in addition to those derived from/associated with the older tradition of abstinence-driven models. Treatment is implemented in a range of environments—such as ambulatory and within-institution—-that can include controlled environments. Editor's note. Address correspondence to Nabila El-Bassel, Social Intervention Group, Columbia University School of Social Work, 1255 Amsterdam Avenue, New York, NY 10027; E-mail: ne5@ columbia.edu
} 
In a study among a random sample of 356 men recruited from seven methadone treatment programs in New York City, we found that $58 \%$ of the men reported ever perpetrating physical and/or sexual IPV, and 38\% admitted to perpetrating physical and/or sexual IPV in the past 6 months (El-Bassel et al., 2007). Among this sample, $32 \%$ reported ever sexually coercing their female partners (forced sex without using physical force), and $21 \%$ had sexually coerced their partners in the past 6 months; $16 \%$ reported ever physically forcing their partners to have sex against their will (rape), and 7\% reported physically forcing their partner to have sex in the past 6 months. Perpetration rates of IPV in this study were higher among men who reported that their female partners were using drugs compared with those with non-drug-using female partners (El-Bassel et al., 2007).

High rates of IPV may be playing a major role in fueling the heterosexual transmission of HIV, as condoms are less likely to be used by partners in long-term relationships where IPV is present. In 2006, women composed $26 \%$ of all HIV/AIDS cases in the United States, and of these, $73 \%$ were infected through heterosexual contact (Centers for Disease Control and Prevention, 2006). In this same year, females made up 27\% of new HIV cases in New York City, and of these women, 63\% were infected through heterosexual intercourse (New York City Department of Health and Mental Hygiene, 2007).

Research suggests that the relationships between experiencing IPV and different HIV transmission risks among heterosexual women are multifaceted and complex. Accumulating research conducted with heterosexual women has found that experiencing IPV is associated with (1) engaging in unprotected sex (Bassuk et al., 1997; Cunningham et al., 1994; El-Bassel et al., 2005a; Fernandez, 1995; Gielen, McDonnell, \& Ocampo, 2002; Gilbert, El-Bassel, Rajah, et al., 2000; Hamburger et al., 2004; Raj, Silverman, \& Amaro, 2004; Saul, Moore, Murphy, \& Miller, 2004; Tucker, Wenzel, Elliott, Marshall, \& Williamson, 2004; Wingood \& DiClemente, 1997; Wyatt, 1991), (2) higher rates of sexually transmitted infections (STIs; El-Bassel, Gilbert, Schilling, \& Wada, 2000; Hogben et al., 2001; Rodriguez, Szkupinski Quiroga, \& Bauer, 1996; Wu, El-Bassel, Witte, Gilbert, \& Chang, 2003), (3) having sex with multiple partners (Gilbert, El-Bassel, Rajah, et al., 2000; Rich et al., 1999; Wu et al., 2003), (4) trading sex for money or drugs (Beadnell, Baker, Morrison, \& Knox, 2000; El-Bassel, Gilbert, Schilling, et al., 2000), (5) having sex with injecting drug users (Gilbert, El-Bassel, Rajah, et al., 2000; Rich et al., 1999), and (6) having sex with HIV-positive partners (El-Bassel et al., 2005a).

Emerging research has also found associations between perpetration of IPV and engaging in HIV risk behaviors among heterosexual men (El-Bassel, Fontdevila, et al., 2001; Gilbert, El-Bassel, Wu, \& Chang, 2007; Raj et al., 2006). A cross-sectional study with a nonrandom sample of 283 sexually active young adult men recruited from an urban community health center found that participants who reported perpetrating IPV during the past year were significantly more likely to report (1) inconsistent or no condom use, (2) forced vaginal sex without a condom, and (3) sex with multiple female partners (Raj et al., 2006). A cross-sectional study with 273 men in methadone treatment programs found that men who reported perpetration of IPV were more likely to have had more than one intimate partner and more likely to have had sex with a druginjecting sexual partner than their counterparts (El-Bassel, Fontdevila, et al., 2001).

Our recent longitudinal research with women and men in methadone treatment further suggests that these multifaceted relationships between IPV and HIV risks are bidirectional (El-Bassel, Gilbert, Wu, Go, \& Hill, 2005b; Gilbert et al., 2007). In our longitudinal study of a random sample of 416 women in methadone treatment in New York City who received repeated assessments at baseline (wave 1), 6 months (wave 2), and 12 months (wave 3), we found that women who always reported using condoms at wave 2 were significantly less likely to report experiencing IPV at wave 3 than women who reported no or inconsistent condom use at wave 2 after controlling for potentially confounding sociodemographic variables assessed at wave 1 (El-Bassel et al., 2005b). Similarly, increased risk of IPV at wave 3 was associated with self-reported STIs at wave 2. Study findings also suggested that experiencing IPV at wave 2 decreased the likelihood of always using condoms and requesting partners to use condoms at wave 3 (El-Bassel et al., 2005b). In our longitudinal study of a random sample of 356 men on methadone, we found (1) that perpetration of IPV in the past 6 months at wave 1 was associated with having more than one intimate partner and buying sex at subsequent waves and (2) that no condom use, injecting drugs, and sexual coercion at wave 1 were associated with subsequent IPV (Gilbert et al., 2007).

In this article, we discuss a number of overlapping contexts found in the literature to explain the bidirectional, multifaceted links between IPV and HIV risks among drug-involved women. These contexts include sexual coercion, fear of violence, negotiation of condom use, extradyadic relationships, disclosure of HIV seropositivity or STIs to intimate partners, drug involvement of women and their male partners, relationship dependencies, and sex ratio imbalances. These contexts overlap, but for the purpose of this article, we present each context separately, using research from the United States, primarily from our studies conducted in New York City. The article also discusses the challenges that substance user treatment programs face in dealing with female clients who experience IPV and the need for integrated HIV prevention approaches that consider the contexts that link IPV and HIV risks.

\section{MECHANISMS LINKING IPV AND HIV RISKS AMONG DRUG-INVOLVED WOMEN}

\section{Sexual Coercion}

Growing research suggests that sexual coercion is one of the major contexts associated with HIV transmission risks 
(Beadnell et al., 2000; Maman, Campbell, Sweat, \& Gielen, 2000; Wingood \& DiClemente, 1998), especially for drug-involved women (Frye, El-Bassel, Gilbert, Rajah, \& Christie, 2001). In several of our studies with women in methadone treatment, we found that women who reported experiencing sexual IPV were more likely to report never using condoms, compared with women who did not report such IPV (El-Bassel, Gilbert, Schilling, et al., 2000; El-Bassel et al., 2005a; Gilbert, El-Bassel, Schilling, et al., 2000). This finding is consistent with other studies that have found an association between sexual coercion and lack of condom use (Beadnell et al., 2000; Frye et al., 2001; Go et al., 2003; Maman et al., 2000; Wingood \& DiClemente, 1998).

Data from in-depth interviews that we conducted with 38 women in methadone treatment in New York City showed that most reported that they consistently forgo requesting condoms when they are pressured into having sex by an intimate partner, fearing that such requests may further provoke their partner and jeopardize their safety (El-Bassel, Gilbert, Schilling, et al., 2000). The goal of women in these forced encounters is to avoid physical harm and to ensure that the experience is over as quickly as possible (El-Bassel, Gilbert, Schilling, et al., 2000; El-Bassel et al., 2005a). Sexual coercion creates a context of male dominance and control that strips women of the power to negotiate their sexual health needs (El-Bassel, Gilbert, Schilling, et al., 2000). In another qualitative study conducted with 62 men on methadone in New York City who perpetrated IPV against their female partners, the majority reported that women are not to be believed when they refuse sex (Fontdevila et al., 2005). The men reported that women really want to have sex; therefore, forcing sex is perceived as a normative reaction among most of these men (Fontdevila et al., 2005).

Research has also linked sexual coercion to risks of HIV and other STIs, in that sexual coercion and rape increases the likelihood of vaginal lacerations and abrasions when force is used (Jenny et al., 1990). Vaginal, anal, and urethral trauma from forced sex can lead to increased transmission of microorganisms through direct transmission into the bloodstream or backflow into the urethra (Jenny et al., 1990).

\section{Fear of IPV and HIV Risk}

Fear of partner violence has been implicated as a risk factor for having unprotected sex in several qualitative and quantitative studies (El-Bassel, Gilbert, Schilling, et al., 2000; Gilbert, El-Bassel, Schilling, et al., 2000; Morrill \& Ickovics, 1996; Wingood \& DiClemente, 1997). In indepth interviews with women on methadone, the majority indicated that after experiencing IPV, some women may be hesitant to attempt to negotiate condom use as well as afraid to refuse unprotected sex (El-Bassel, Gilbert, Schilling, et al., 2000; Gilbert, El-Bassel, Schilling, et al., 2000). A cross-sectional study of 125 African American women in low-income housing found that women who experienced sexual IPV were more likely than their nonabused counterparts to report being afraid of asking their partners to wear condoms because of the potential violent reaction it may provoke (Kalichman, Williams, Cherry, Belcher, \& Nachimson, 1998). This context of fear of violence renders women unable to shield themselves from HIV and other STIs. The failure to use condoms in relationships where the threat of IPV is present may also explain the link between IPV and STIs found in several studies (El-Bassel, Gilbert, Schilling, et al., 2000; Gilbert, El-Bassel, Schilling, et al., 2000; Hogben et al., 2001; Rodriguez et al., 1996; Wu et al., 2003).

\section{Negotiating Condom Use and IPV}

Consistent with other research among women in methadone treatment (El-Bassel et al., 2005a, 2005b), we found that requesting or insisting that a partner use condoms was associated with experiencing IPV (Gilbert, El-Bassel, Schilling, et al., 2000). Women who always use condoms in their intimate relationships may not need to negotiate with their partners because the norm has already been established. In contrast, women who sometimes use condoms and attempt to initiate or renegotiate their use may increase their risk of IPV. Their partners may perceive their inconsistent or new requests to use condoms as a breach of gender role expectations and a threat to the male's sexual decision-making power (El-Bassel et al., 2005a).

Furthermore, if a woman suspects that her partner is having extradyadic affairs, injecting drugs, or engaging in other risky behaviors, requesting that he use condoms or get tested for HIV may signal to him a lack of trust or caring (El-Bassel, Gilbert, Rajah, et al., 2000; Gilbert, El-Bassel, Schilling, et al., 2000; Kelly \& Kalichman, 1995; Kelly et al., 1993; Melendez, Hoffman, Exner, Leu, \& Ehrhardt, 2003). For some men, it may even imply that she has engaged in risky behaviors and may be perceived as a sign of infidelity on her part and a breach of gender role expectations (El-Bassel, Gilbert, Rajah, et al., 2000; Fontdevila et al., 2005). Such perceptions may trigger jealousy and threaten the stability of the couple, increasing the likelihood of abuse (O'Leary \& Wingood, 2000), as some men resort to using physical and/or sexual IPV as a mechanism to repair their masculine self-esteem and maintain male power. In our qualitative study with 62 men on methadone who perpetrated IPV against their female partners, all agreed that requesting condoms in a committed relationship creates mistrust and conflict between partners that may ignite physical and sexual abuse. In in-depth interviews with 38 women in methadone treatment, several women indicated that they had tried to protect themselves from HIV and other STIs by refusing sex or at least refusing unprotected sex (El-Bassel, Gilbert, Schilling, et al., 2000). To strike back against these refusals, some women reported that their partners would counteract with violence or threats of violence (El-Bassel, Gilbert, et al., 1998; El-Bassel, Gilbert, Rajah, et al., 2000; Gilbert, El-Bassel, Schilling, et al., 2000). 


\section{Engaging in Extradyadic Affairs to Escape Relationship Conflict and IPV}

The relationship instability associated with IPV may increase the likelihood that both partners will engage in extradyadic relationships as an exit strategy. Such affairs may also be pursued by a male partner as a strategy of retaliation, often with the explicit purpose of creating jealousy and a desire in a female partner to compete for reconnection (Gilbert et al., 2007). In such cases where women fear losing their partners, it is unlikely that they will insist on using condoms, even when they know that their partners are sexually active with other women (Beadnell et al., 2000). Although research has yet to document the precise temporal sequences of shifting between intimate and extradyadic partners, lack of protection in these concurrent relationships has the potential to increase the likelihood of transmission of HIV and other STIs.

\section{Disclosure of HIV/STIs and IPV}

Findings on the relationship between disclosure of STIs and HIV seropositivity and IPV have been somewhat mixed. In a study with $50 \mathrm{HIV}$-positive women, the women experienced positive (acceptance, understanding) as well as negative consequences (rejection, abandonment, physical abuse) following disclosure of their HIV status (Gielen, O'Campo, Faden, \& Eke, 1997). In our longitudinal study with a random sample of 416 women in methadone treatment, being HIV positive increased the risk of subsequent IPV at 12-month follow-up (El-Bassel et al., 2005b), which is consistent with previous research that found an association between disclosure of an STI or HIV positivity and subsequent IPV (Gielen, O'Campo, Anderson, Keller, \& Faden, 2000; Gielen et al., 1997; North \& Rothenberg, 1993; Rothenberg \& Paskey, 1995). Furthermore, qualitative research suggests that abused women who tested positive for HIV or other STIs reported that they were fearful of disclosing their status, knowing that it may incite IPV (El-Bassel, Gilbert, Rajah, et al., 2000).

\section{RELATIONSHIP DEPENDENCIES}

Research with drug-involved women has identified three overlapping relationship dependencies on intimate partners- housing and financial, drug, and social-that increase risks for both IPV and HIV.

\section{Housing and Financial Dependency}

In our longitudinal study, we found that women who were dependent on their partner for their housing were three times more likely not to ask him to use condoms than their counterparts (El-Bassel et al., 2005b). Women who reported that they depend on their partners for household expenses are twice as likely to report IPV as women who did not report that their partner pays their household expenses. These findings were also supported from our indepth interviews conducted with women on methadone who indicated that when they need money, they acquiesce to their partners' demands, and their partners control when and how they have sex (El-Bassel, Gilbert, Rajah, et al., 2000).

\section{Dependent on Partner for Drug Supply}

In the longitudinal study, methadone-treated women who reported that their partners supplied their illicit drugs were twice as likely never to ask their partner to use condoms as women whose partners did not supply their drugs (ElBassel et al., 2005b). In our focus groups and in-depth interviews we learned that while most methadone-treated women relied on their partners to supply them with drugs, others said that they pay for and procure drugs for the male partners, especially when the partner is going through withdrawal (Gilbert, El-Bassel, Rajah, et al., 2000). Depending on the male partner to support their drug habit makes women more likely to acquiesce to unprotected sex and other risky behaviors. In addition, substance abuse ${ }^{2}$ may lead women to exchange sex for money or drugs in risky unprotected encounters (El-Bassel, Gilbert, Rajah, et al., 2000; Sterk, 1999). These women may also feel pressured to sell sex to supply their addicted partners with drugs (El-Bassel, Gilbert, Rajah, et al., 2000; Sterk, 1999).

\section{Social Dependency}

Social isolation that stems from the controlling behaviors of the male intimate sexual partner is common among drug-involved women (Gilbert, El-Bassel, Rajah, Foleno, $\&$ Frye, 2001). Drug-involved women have fewer friends, especially female friends (El-Bassel, Gilbert, et al., 2001). In a study of the social network profiles of women in methadone treatment, more than two thirds were isolated and had few non-drug-involved network members who they could turn to for any type of support (El-Bassel, Cooper, \& Chen, 1998). In a random sample of 416 women on methadone, we found that $39 \%$ indicated that their partner prevented them from going out; $14 \%$ were prevented from getting drug treatment; and 13\% said that their partners kept them "as prisoners" (El-Bassel et al., 2005a). Such controlling behaviors may undermine women's ability to negotiate condom use and safer relationships with their partners.

\section{SEX RATIO IMBALANCE AND PERCEIVED SHORTAGE OF ELIGIBLE MALE PARTNERS}

The cultural value and social status placed on having a male partner often keeps women from leaving abusive relationships that put them at risk for HIV transmission. In the in-depth interviews with women on methadone, they frequently emphasized the social value that their friends and people around them placed on the notion of having an intimate partner (El-Bassel, Gilbert, Rajah, et al., 2000); this was especially true of African American women.

Research has suggested that the sex ratio imbalance in the African American community, where the number of

\footnotetext{
${ }^{2}$ The journal's style utilizes the category substance abuse as a diagnostic category. Substances are used or misused; living organisms are and can be abused. Editor's note.
} 
females substantially outpaces the number of males, exacerbates power imbalances within intimate relationships, rendering African American women with less power to negotiate safe relationships (Mize, Robinson, Bockting, \& Scheltema, 2002). Moreover, in a social context where the number of "available" African American men may be limited because of incarceration and a higher death rate, women may alter their self-protective behaviors in ways that are driven by a fear of losing the present partner and not being able to find another. For instance, a study of low-income African American women found that fear of a negative partner reaction-and, presumably, fear of losing the partner as a result-was associated with lower levels of condom use (Amaro \& Raj, 2000). El-Bassel and colleagues (2000) suggest that the fear of disrupting a partnership when an alternative partner may not be available plays an important role in determining whether or not a woman is willing to insist on condom use. Moreover, the fear of losing a partner not only may inhibit African American women from requesting or insisting on condoms but may also prevent them from resisting IPV or refusing drug use within an intimate partnership (Mize et al., 2002).

\section{THE ROLE OF DRUG AND ALCOHOL USE IN FUELING IPV AND HIV RISK}

Women's Drug Use as a Mediator of IPV and HIV Risk Drug and/or alcohol dependency by either or both partners in a couple may mediate the multifaceted relationships between experiencing IPV and engaging in HIV risks. Numerous studies have linked drug and alcohol use with having unprotected sex, sex with a risky partner, sex with multiple partners, and exchanging sex for money or drugs, as well as with risks of HIV and other STIs (Chiasson et al., 1990; Edlin et al., 1992, 1994). Accumulating research has also found significant associations between experiencing IPV and using different drugs among women (Brewer, Fleming, Haggerty, \& Catalano, 1998; Cottler, Compton, Mager, Spitznagel, \& Janca, 1992; El-Bassel, Gilbert, Rajah, et al., 2000), including alcohol use (Cunradi, Caetano, \& Shafer, 2002; Field \& Caetano, 2003; Mcnutt, Carlson, Persaud, \& Postmus, 2002), cocaine and marijuana use (Chermack, Fuller, \& Blow, 2000; El-Bassel, Gilbert, Rajah, et al., 2000; ElBassel et al., 2005b), heroin use (El-Bassel, Gilbert, Witte, et al., 2003; El-Bassel et al., 2005b), and tranquilizer use (Brewer, Fleming, Haggerty, \& Catalano, 1998; ElBassel et al., 2004). Among a probability sample of 3,003 women, Kilpatrick, Acierno, Resnick, Saunders, and Best (1997) found that women's drug use at a single point in time increased their odds of experiencing a violent assault in the subsequent year by a factor of 1.84 , after controlling for background factors. This study also estimated that new assaults doubled the risk of drug use in the subsequent year. A recent study with women in methadone treatment conducted in New York City by the authors of this article examined whether frequent drug use increased subsequent sexual and physical IPV and whether experiencing IPV increased the likelihood of subsequent frequent drug use, using data from wave 2 (6 months postbaseline) and wave 3 (12 months postbaseline; El-Bassel et al., 2005b). Findings showed that women who reported frequent crack cocaine use at wave 2 were four times more likely than women on methadone who did not use crack to report physical and sexual abuse at wave 3 . Women who used marijuana at wave 2 were twice as likely as their counterparts to report physical and sexual abuse at wave 3. This study also found that women who reported IPV at wave 2 were three times more likely to report heroin use at wave 3 than their counterparts who did not report physical and sexual IPV (El-Bassel et al., 2005b).

Several factors may explain these temporal relationships between using drugs and experiencing IPV among women. First, women under the influence of drugs or alcohol are less likely to identify risky situations or pick up on cues of impending sexual coercion and less able to negotiate condom use in such encounters (El-Bassel, Gilbert, Rajah, et al., 2000). For example, women who frequently use crack cocaine may have impaired judgment, making it more difficult for them to discern when their partner's words or actions are escalating to a threatening level (Miller, Gold, \& Mahler, 1991; Spunt, Goldstein, Bellucci, \& Miller, 1990). Second, several studies have also documented the perilous and degrading circumstances under which women who exchange sex for money or drugs operate where coercive sex is common and condom use infrequent (Edlin et al., 1994; El-Bassel et al., 1996; Fullilove, Lown, \& Fullilove, 1992; Irwin et al., 1995; Lown, Winkler, Fullilove, \& Fullilove, 1993). In our qualitative study, women indicated that if their intimate partners provided them with drugs their partners would often expect sex in return (El-Bassel, Gilbert, Rajah, et al., 2000). Finally, emerging qualitative research suggests that drug use among abused women often occurs as a self-medication response to ameliorate the emotional and physical pain of experiencing IPV (Gilbert et al., 2001; Sterk, 1999).

\section{The Low Social Status of Drug-Involved Women}

The low social status of women who use crack cocaine may give their partners greater entitlement to abuse such women (Gilbert, El-Bassel, Rajah, et al., 2000; Gilbert et al., 2001; Sterk, Dolan, \& Hatch, 1999). Verbal abuse, which is often aimed at the perceived low social status, sexual promiscuity, and the stigma of being a drug-dependent woman, may further disempower druginvolved women from negotiating safer sex. (Gilbert, ElBassel, Rajah, et al., 2000; Gilbert et al., 2001; Sterk, 1999). Drug-dependent women are often considered "sexually promiscuous" or "damaged goods"; they are perceived as violating traditional gender role norms and, thus, more deserving of abuse (Miller, Downs, \& Testa, 1993). Experiencing IPV and then taking sexual risks may thus occur as an extension of the unequal distribution of sexual, social, and economic power among women, low social status of drug-involved women, and gender inequality between men and women within the drugusing subculture. At the same time, IPV may also occur 
as an extension of a violent subculture associated with crack in economically disadvantaged urban communities (Inciardi, Pottieger, Forney, Chitwood, \& McBride, 1991; Johnson, Williams, Sanabria, \& Dei, 1989).

\section{Male Partner's Substance Use as a Mediator of IPV and HIV Risk}

Substance use among male partners may further mediate the relationship between IPV and HIV risks. In our study among 356 men on methadone, conducted in New York City, we found that illicit drug use by both male and female partners was significantly associated with perpetration of severe sexual and physical IPV (El-Bassel et al., 2007). Drug and alcohol use by perpetrators tends to intensify feelings of paranoia, jealousy, and irritability as well as impair judgments; these psychopharmacological effects may increase the likelihood of IPV and decrease the ability to use condoms (Gilbert et al., 2001; Straus $\&$ Gelles, 1990). In qualitative research with women on methadone, several women described how their partners became easily irritated when experiencing withdrawal from drugs, and this irritation increased their risk of sexual IPV that was often followed by physical IPV (ElBassel, Gilbert, Schilling, et al., 2000). A number of women said that their partners insisted on having sex after physical violence, which they viewed as a way of restoring their control over the relationship and a return to status quo (El-Bassel, Gilbert, Rajah, et al., 2000). Qualitative research further suggests that substance use by the woman or her partner tends to increase her partner's expectations for unwanted and unprotected sex (ElBassel, Gilbert, Schilling, et al., 2000; Sterk, 1999). A woman's refusal to have sex under these heightened expectations may trigger a violent response from her partner, especially if he is under the influence of alcohol or drugs.

Both victims and perpetrators tend to believe that perpetrators under the influence of drugs or alcohol may not be held accountable for sexual coercion. Qualitative research suggests that women often attributed their experiences of forced sex to drugs rather than to their partner's behavior (El-Bassel, Gilbert, Schilling, et al., 2000). Such attributions may ironically permit men under the influence of drugs greater power and control in sexual situations. As long as drugs are blamed for men forcing sex upon their partners, the men are not held accountable for their own actions. Such social expectations may enable partners to continue perpetrating sexual IPV (Gilbert et al., 2001; Straus \& Gelles, 1990).

\section{Couple's Substance Use and Discrepancies of Sexual Desire}

Discrepancies in sexual desire while both male and female partners are under the influence of drugs or alcohol may also create conflict that results in sexual coercion. In our in-depth interviews with 38 women, some women attributed the increased likelihood of sexual IPV to disparities in sexual desire under the influence of drugs (El-Bassel, Gilbert, \& Rajah, 2003). While women often felt a diminished desire for sex, particularly under the influence of crack, they reported that their partner often expressed an increased sexual desire after using crack and/or heroin but a decreased ability to perform (El-Bassel, Gilbert, \& Rajah, 2003). Findings from these in-depth interviews suggest that a male partner under the influence of drugs would continue to insist on sex despite difficulties with sustaining an erection or ejaculating.

Several women also reported that they were more likely to endure forced sex while they were under the influence of drugs. Several women also described being forced to sell sex to procure drugs for their partners. After the fact, the same partner would physically hurt her for selling sex, and then, to make up while still under the influence of the drugs that she purchased, he would force her to have sex with him to restore his power in the relationship (ElBassel et al., 2003).

\section{CHILDHOOD SEXUAL ABUSE AND POST-TRAUMATIC STRESS DISORDER AS MEDIATORS OF IPV AND HIV RISK}

The relationship between experiencing IPV and engaging in risky sexual behavior may be further mediated by childhood sexual abuse (CSA) and post-traumatic stress disorder (PTSD), which have been found to be associated with IPV (Dansky, Byrne, \& Brady, 1999; Schiff, El-Bassel, Engstrom, \& Gilbert, 2002; Wathen \& MacMillan, 2003) and HIV risk behaviors (Hutton et al., 2001; Lewis, 2005). Previous research indicates that between $56 \%$ and $84 \%$ of women in drug treatment programs have experienced CSA (Cohen \& Densen-Gerber, 1982; Freeman, Collier, \& Parillo, 2002; Gil-Rivas, Fiorentine, Anglin, \& Taylor, 1997; Medrano, Desmond, Zule, \& Hatch, 1999; Paone, Chavkin, Willets, Friedman, \& Des Jarlais, 1992; Teets, 1995). This range of prevalence rates is two to three times higher than the range of prevalence rates $(6 \%-45 \%)$ found in community-based samples of women (Geffner, 1992; Hashima \& Finkelhor, 1999; Morrow \& Smith, 1995; Wyatt \& Newcomb, 1990). Results from numerous cross-sectional studies suggest that CSA is the event that most often leads to PTSD among women, particularly among drug-involved women (Breslau, Davis, Andreski, \& Peterson, 1991; Kessler, Sonnega, Bromet, Hughes, \& Nelson, 1995; Resnick, Kilpatrick, Dansky, Saunders, \& Best, 1993; Winfield, George, Swartz, \& Blazer, 1990). An accumulation of data indicates that PTSD is a salient, if not core, component of a complex of symptoms related to CSA (Astin, Ogland-Hand, Coleman, \& Foy, 1995; Freeman, Parillo, Collier, \& Rusek, 2001; Gil-Rivas et al., 1997). Furthermore, previous research has found relationships between PTSD symptoms of disassociation and hyperarousal and engaging in sexual HIV risk behaviors among women (Hutton et al., 2001; Lewis, 2005). Thus, there exist pernicious, cyclical relationships among the co-occurring problems of PTSD, IPV, substance abuse, and HIV risk. 


\section{CHALLENGES DRUG TREATMENT PROGRAMS FACE IN DEALING WITH IPV AND ITS RELATIONSHIP TO HIV}

A growing body of evidence suggests that interpersonal stress and relationship conflicts including IPV among women in drug user treatment programs are major triggers for relapse (Leshner, 1998; McKay, Rutherford, Cacciola, Kabasakalian-McKay, \& Alterman, 1996), continued drug use, and attrition from substance user treatment programs (Gilbert et al., 2001; Gil-Rivas et al., 1997; Melchior, Huba, Brown, \& Slaughter, 1999). Risks of IPV may heighten upon a woman's entry into drug user treatment because her partner may perceive her attempts to "get clean" as a sign of abandonment. He may retaliate with sexual and physical IPV or extradyadic sex, increasing her risks for HIV and other STIs (Amaro, 1995; Gilbert, El-Bassel, Schilling, et al., 2000). Moreover, abusive partners will often attempt to limit a woman's access to drug user treatment or services and social support with threats or controlling behaviors and dependencies (Gilbert et al., 2001; Gilbert, El-Bassel, Schilling, et al., 2000).

Although substance user treatment programs have played a significant role in reducing the spread of HIV among drug-involved women, and some progress has been made to include an assessment for IPV, especially at program entry, IPV is not always addressed in substance user treatment programs, and referrals to deal with IPV problems may not occur. This may be explained by high counselor caseloads, a lack of training of program staff to assess for IPV, few resources, and a scarcity of treatment approaches in substance abuse programs to deal with IPV (Kunins, Gilbert, Whyte, Meissner, \& Zachary, 2007). Referrals may not occur because the number of IPV treatment programs or battered women's shelters that will accept drug-involved women is low. Many battered women's shelters reject drug-involved women completely. In the past several years, there has been some shift and increase in the level of awareness of IPV among health practitioners and counselors in substance user treatment programs; however, more needs to be done to address this serious issue. Standard protocols for assessment, safety planning, and referrals to address IPV among individuals in drug user treatment programs need to be available to all female clients. If a woman is currently involved with an abusive partner, counseling staff should be at least minimally trained to develop a safety plan with her and provide referrals for ongoing treatment for problems related to IPV.

\section{IMPLICATIONS FOR HIV PREVENTION THAT ADDRESS THE CO-OCCURRING PROBLEMS}

To date, there is a paucity of empirically tested HIV prevention interventions designed for women to specifically address the problem of concurring HIV risks, IPV, and substance use. A growing number of researchers, along with a policy report from the World Health Organization (1997), have emphasized the need for HIV prevention interventions to incorporate IPV prevention, particularly for drug-involved women (Belenko, Lin, O'Connor, Sung, \& Lynch, 2005; El-Bassel et al., 2005a; Gilbert, El-Bassel, Schilling, et al., 2000; Kalichman et al., 1998; Maman et al., 2000; Raj et al., 2004; Wingood \& DiClemente, 1997; Wu et al., 2003). The disproportionately high prevalence rates of IPV among drug-involved women underscore the need to develop HIV prevention intervention models that synergistically address the multiple contexts that drive the co-occurring problems of HIV, IPV, and substance abuse. Integrated HIV prevention intervention approaches should take into consideration the different contexts that increase HIV risks presented in this article, such as sexual coercion, fear of violence, negotiating condom use, disclosure of HIV and other STIs to partners, attitudes toward drug-involved women and gender role power imbalances, the drug use of women and their male partners, PTSD and trauma, and relationship dependencies.

Such integrated HIV risk reduction intervention strategies may include the following cognitive behavioral components: (1) raising awareness of the interpersonal contexts and triggers of HIV risk behavior and IPV, for example, considering how requests for condom use in an intimate relationship may trigger sexual and physical violence and how fear and experience of IPV prevents some drug-involved women from protecting themselves from HIV; (2) developing an accurate appraisal of risk of HIV and IPV as well as increasing safety planning, problem solving, and sexual communication skills to negotiate safer relationships with their partners; and (3) increasing access and utilization of services and bolstering informal social support to help women establish and maintain relationship safety. It is very important that the integrated HIV prevention intervention approaches take into account the balance of power in intimate relationships, level of sexual communication and negotiation skills, relationship dependencies, and history of trauma and PTSD.

Failure to address the co-occurring problems of HIV risk and IPV in an integrated approach for women in drug user treatment may not only increase their risk of HIV but also jeopardize their recovery and safety. Moreover, in order to change social norms toward violence against women, HIV prevention efforts should also target all women and men attending substance user treatment programs and raise their awareness of the scope of violence against women and the resources available for IPV. Informational prevention strategies can be disseminated through workshops, the distribution of brochures, and media such as informative videos shown in waiting rooms of clinics. Such dissemination of information in conjunction with an integrated behavioral intervention can focus on building a continuum of relationship safety strategies that synergistically focus on both IPV and HIV prevention among drug-involved women.

In sum, HIV continues to be a serious epidemic among drug-involved women in New York City, disproportionately affecting African American and Latina women, the majority of whom are infected through heterosexual contact (New York City Department of Health and Mental Hygiene, 2007). Despite a quarter of a century of 
accumulated research demonstrating that behavioral prevention interventions can curb HIV risks among adult women, few US evidenced-based HIV intervention models have focused exclusively on drug-involved women. In order to reduce the HIV epidemic among women in drug user treatment programs in New York City, special attention needs to be paid to the design, testing, and implementation of women-specific HIV prevention approaches that address the co-occurring mechanisms and mediators related to HIV and drug abuse described in this article. Our research on HIV and IPV among women in drug user treatment programs in New York City has elucidated a number of mechanisms that link HIV and IPV (sexual coercion, fear of violence, disclosure of HIV and STIs, relationship dependencies, and drug use of the perpetrators and the victims) and mediators (CSA and PTSD).

Addressing the mechanism and mediators of IPV in HIV prevention is critically needed because IPV plays a significant role in escalating heterosexual transmission of HIV. Condoms are less likely to be used by partners in a long-term relationship where IPV is present. Although drug user treatment programs in New York City have made some progress in recognizing that IPV is a risk for $\mathrm{HIV}$, and a few programs include an assessment for IPV in their intake protocols, the use of evidenced-based interventions in the co-occurring problems of HIV and IPV have rarely been implemented. This is because of the lack of available evidenced-based models that incorporate both IPV and HIV, and as a result, less attention is paid to these co-occurring problems among women. Addressing this shortcoming would have important public health implications for HIV prevention for drug-involved women in New York City.

\section{Declaration of Interest}

The authors report no conflicts of interest. The authors alone are responsible for the content and writing of the article.

\section{THE AUTHORS}

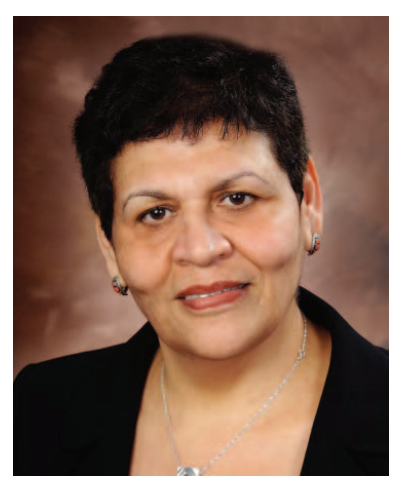

Dr. Nabila El-Bassel

is a Professor at the Columbia University School of Social Work and Director of the Social Intervention Group (SIG), which was established in 1990 as a multidisciplinary research center on global health. Dr. El-Bassel is also the Director of the Columbia University Global Health Research Center in central Asia. The Center brings together leading multidisciplinary global health experts and creates crosscutting partnerships among governments, nongovernmental organizations, and academic institutions in central Asia. Dr. El-Bassel has been funded extensively by the National Institute of Mental Health and the National Institute on Drug Abuse. She has designed and tested
HIV intervention and prevention models for women, men, and couples and has studied the intersecting epidemics of HIV and violence against women.

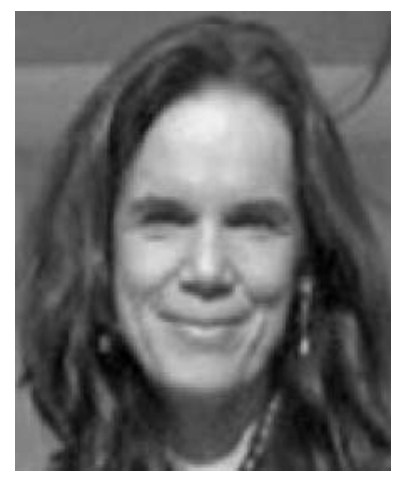

Louisa Gilbert, Ph.D., is the Codirector of the Global Health Research Center of central Asia and also the Codirector of the SIG at Columbia University School of Social Work. She has served as a Coinvestigator and Investigator on three National Institute of Mental Health (R01) studies and three National Institute on Drug Abuse (R01) studies. She has coauthored more than 50 articles with Dr. El- Bassel and has presented papers at several international and national conferences on HIV/AIDS and substance abuse. Her current area of research examines the relationship between IPV and HIV risk among drug-involved women, with a focus on designing gender-specific HIV prevention interventions that address IPV and other traumas.

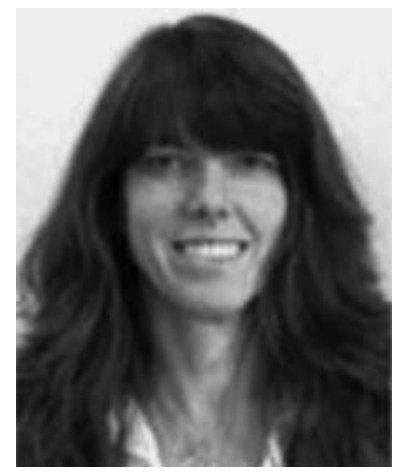

Susan Witte, Ph.D., L.C.S.W., is an Associate Professor at the Columbia University School of Social Work and Associate Director of the Columbia University SIG. Witte's research at the SIG focuses on the development and testing of prevention and treatment interventions targeting the co-occurrence of HIV/AIDS risk behaviors, substance abuse, and interpersonal violence and the corresponding mental health consequences of these issues in vulnerable populations. Her current research is focused on the use of multimedia and Web-based technologies in the dissemination of HIV prevention and social-work-related programming, the promotion of female-initiated reproductive health technology including the female condom, and the utility of relationship- and family-based interventions, which move beyond the traditional target of individual behavior change to couples and families. Witte is principal investigator on a number of clinical trials funded by the National Institutes of Health and has presented her clinical and research findings at national and international social work, mental health, and public health conferences.

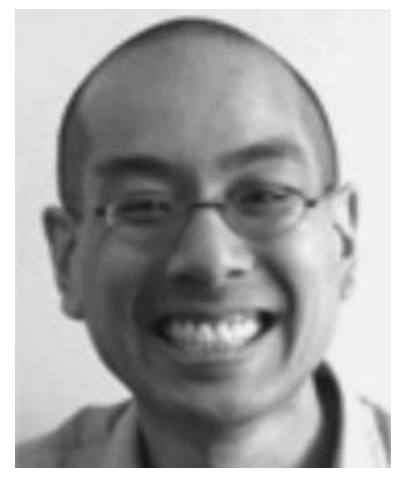

Elwin Wu, Ph.D., is an Assistant Professor at the Columbia University School of Social Work and an Associate Director at the SIG, where he and his colleagues conduct research targeting the intersection and overlap of HIV/ AIDS, substance abuse, and interpersonal violence. Dr. Wu's program of research covers a range of health services, prevention, and treatment research, all with an emphasis on marginalized populations. His 
current and recent research projects include an examination of the trajectories through the service system of drug-involved men who perpetrate IPV, identification of the key or active ingredients of alternative to incarceration programs in New York City, and adapting/developing novel behavioral HIV/STI preventive interventions for drug-involved men of color who have sex with men.

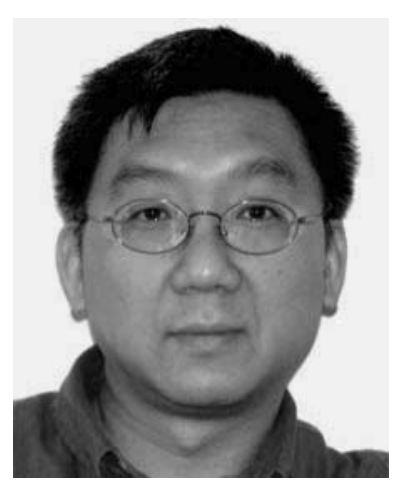

Mingway Chang, Ph.D., is a Sociologist and Statistician at the SIG. Dr. Chang has been developing and conducting quantitative analyses of data from observational studies and clinical trials focusing on behavioral intervention in the areas of HIV/AIDS, IPV, and substance abuse. His research interests include mathematical methods for theory building, dyadic data analysis, structural equation modeling, and social network analysis. Recently, Dr. Chang is working on examining discrepancies between partners' responses in couple data and is developing an analytical approach to deal with measurement errors in couple data.

\section{REFERENCES}

Amaro, H. (1995). Love, sex and power: Considering women's realities in HIV prevention. American Psychologist, 50, 437-447.

Amaro, H., Fried, L. E., Cabral, H., \& Zuckerman, B. (1990). Violence during pregnancy and substance abuse. American Journal of Public Health, 80, 575-579.

Amaro, H., \& Raj, A. (2000). On the margin: The realities of power and women's HIV risk reduction strategies. Sex Roles, 42, 723-749.

Astin, M. C., Ogland-Hand, S. M., Coleman, E. M., \& Foy, D. W. (1995). Posttraumatic stress disorder and childhood abuse in battered women: Comparisons with maritally distressed women. Journal of Consulting and Clinical Psychology, 63, 308-312.

Bassuk, E. L., Buckner, J. C., Weinreb, L. F., Browne, A., Bassuk, S. S., Dawson, R., et al. (1997). Homelessness in female-headed families: Childhood and adult risk and protective factors. American Journal of Public Health, 87, 241-248.

Beadnell, B., Baker, S. A., Morrison, D. M., \& Knox, K. (2000). HIV/STD risk factors for women with violent male partners. Sex Roles, 42, 661-689.

Belenko, S., Lin, J., O'Connor, L., Sung, H., \& Lynch, K. (2005). Sexual and physical victimization as predictors of HIV risk among felony drug offenders. AIDS and Behavior, 9, 311-323.

Breslau, N., Davis, G. C., Andreski, P., \& Peterson, E. (1991). Traumatic events and posttraumatic stress disorder in an urban population of young adults. Archives of General Psychiatry, 48, 216-222.

Brewer, D. D., Fleming, C. B., Haggerty, K. P., \& Catalano, R. F. (1998). Drug use predictors of partner violence in opiate dependent women. Violence and Victims, 13, 107-116.

Caetano, R., Nelson, S., \& Cunradi, C. (2001). Intimate partner violence, dependence symptoms and social consequences from drinking among white, black and Hispanic couples in the United States. American Journal of Addiction, 10(Suppl.), 60-69.
Centers for Disease Control and Prevention. (2006). Epidemiology of HIV/AIDS-United States, 1981-2005. Morbidity and Mortality Weekly Report, 55, 589-592.

Chermack, S., Fuller, B., \& Blow, F. (2000). Predictors of expressed partner and non-partner violence among patients in substance abuse treatment. Drug and Alcohol Dependence, 58, 43-54.

Chiasson, M. A., Stoneburner, R. L., Lifson, A. R., Hildebrandt, D. S., Ewing, W. E., Schultz, S., et al. (1990). Risk factors for human immunodeficiency virus type 1 (HIV-1) infection in patients at a sexually transmitted disease clinic in New York City. American Journal of Epidemiology, 131, 208-220.

Cohen, F. S., \& Densen-Gerber, J. (1982). A study of the relationship between child abuse and drug addiction in 178 patients: Preliminary results. Child Abuse \& Neglect, 6, 383-387.

Cottler, L. B., Compton, W. M., Mager, D., Spitznagel, E. L., \& Janca, A. (1992). Post-traumatic stress disorder among substance users from the general population. American Journal of Psychiatry, 149, 664-670.

Cunningham, R. M., Stiffman, A. R., Dore, P., \& Earls, F. (1994). The association of physical and sexual abuse with HIV risk behaviors in adolescence and young adulthood: Implications for public health. Child Abuse \& Neglect, 18, 233-245.

Cunradi, C., Caetano, R., \& Shafer, J. (2002). Alcohol-related problems, drug use, and male intimate partner violence severity among US couples. Alcoholism: Clinical and Experimental Research, 26, 493-500.

Dansky, B. S., Byrne, C. A., \& Brady, K. T. (1999). Intimate violence and post-traumatic stress disorder among individuals with cocaine dependence. American Journal of Drug and Alcohol Abuse, 25, 257-268.

Edlin, B. R., Irwin, K. L., Faruque, S., McCoy, C., Word, C., Serrano, Y., et al. (1994). Intersecting epidemics: Crack cocaine use and HIV infection in inner-city young adults. New England Journal of Medicine, 21, 1422-1427.

Edlin, B. R., Irwin, K. L., Ludwig, D. D., McCoy, H. V., Serrano, Y., Word, C., et al. (1992). High-risk sex behavior among young street-recruited crack cocaine smokers in three American cities: An interim report. Journal of Psychoactive Drugs, 24, 363-371.

El-Bassel, N., Cooper, D., \& Chen, D. R. (1998). Social support and social networks among women on methadone. Social Service Review, 72, 379-401.

El-Bassel, N., Fontdevila, J., Gilbert, L., Voisin, D., Richman, B., \& Pitchell, P. (2001). HIV risks of men in methadone maintenance treatment programs who abuse their intimate partners: A forgotten issue. Journal of Substance Abuse, 13, 115.

El-Bassel, N., Gilbert, L., Frye, V., Wu, E., Go, H., \& Hill, J. (2004). Physical and sexual intimate partner violence among women in methadone maintenance treatment. Psychology of Addictive Behaviors, 18, 180-183.

El-Bassel, N., Gilbert, L., Ivanoff, A., Schilling, R. F., Borne, D., \& Safyer, S. F. (1996). Correlates of crack abuse among incarcerated women: Psychological trauma, social support and coping behavior. American Journal of Drug and Alcohol Abuse, 22, 41-56.

El-Bassel, N., Gilbert, L., Krishnan, S., Schilling, R. F., Gaeta, T., Purpura, S., et al. (1998). Partner violence and sexual HIV-risk behaviors among women in an inner-city emergency department. Violence and Victims, 13, 377-393.

El-Bassel, N., Gilbert, L., \& Rajah, V. (2003). The relationship between drug abuse and sexual performance among women on methadone: Heightening the risk of sexual intimate violence and HIV. Addictive Behaviors, 28, 1385-1403. 
El-Bassel, N., Gilbert, L., Rajah, V., Foleno, A., \& Frye, V. (2000). Fear and violence: Raising the HIV stakes. AIDS Education and Prevention, 12, 154-170.

El-Bassel, N., Gilbert, L., Rajah, V., Foleno, A., \& Frye, V. (2001). Social support among women in methadone treatment who experience partner violence. Violence Against Women, 7, 246-274.

El-Bassel, N., Gilbert, L., Schilling, R. F., \& Wada, T. (2000). Drug abuse and partner violence among women in methadone treatment. Journal of Family Violence, 15, 209-225.

El-Bassel, N., Gilbert, L., Witte, S., Wu, E., Gaeta, T., Schilling, R., et al. (2003). Intimate partner violence and substance abuse among minority women receiving care from an inner-city emergency department. Women's Health Issues, 13, 16-22.

El-Bassel, N., Gilbert, L., Wu, E., Chang, M., \& Fontdevila, J. (2007). Perpetration of intimate partner violence among men in methadone treatment programs in New York City. American Journal of Public Health, 97, 1230-1232.

El-Bassel, N., Gilbert, L., Wu, E., Go, H., \& Hill, J. (2005a). HIV and intimate partner violence among methadone-maintained women in New York City. Social Science \& Medicine, 61, 171-183.

El-Bassel, N., Gilbert, L., Wu, E., Go, H., \& Hill, J. (2005b). Relationship between drug abuse and intimate partner violence: A longitudinal study among women receiving methadone. American Journal of Public Health, 94, 465-470.

Fernandez, M. I. (1995). Latinas and AIDS: Challenges to HIV prevention efforts. In A. O'Leary \& L. S. Jemmott (Eds.), AIDS prevention and mental health (pp. 159-174). New York: Plenum.

Field, C., \& Caetano, R. (2003). Longitudinal model predicting partner violence among white, black, and Hispanic couples in the United States. Alcoholism: Clinical and Experimental Research, 27, 1451-1458.

Fontdevila, J., El-Bassel, N., \& Gilbert, L. (2005). Accounting for HIV risk among men on methadone. Sex Roles, 52, 609-624.

Freeman, R. C., Collier, K., \& Parillo, K. M. (2002). Early life sexual abuse as a risk factor for crack cocaine use in a sample of community-recruited women at high risk for illicit drug use. American Journal of Drug and Alcohol Abuse, 28, 109-132.

Freeman, R. C., Parillo, K. M., Collier, K., \& Rusek, R. W. (2001). Child and adolescent sexual abuse history in a sample of 1,490 women sexual partners of injection drug-using men. Women and Health, 34, 33-53.

Frye, V., El-Bassel, N., Gilbert, L., Rajah, V., \& Christie, N. (2001). Intimate partner sexual abuse among women on methadone. $\mathrm{Vi}$ olence and Victims, 16, 553-564

Fullilove, M. T., Lown, A., \& Fullilove, R. E. (1992). Crack "hos and skeezers": Traumatic experiences of women crack users. Journal of Sex Research, 29, 257-287.

Geffner, R. (1992). Current issues and future directions in child sexual abuse. Journal of Child Sexual Abuse, 1, 1-13.

Gielen, A. C., McDonnell, K. A., \& Ocampo, P. J. (2002). Intimate partner violence, HIV status, and sexual risk reduction. AIDS and Behavior, 6, 107-116.

Gielen, A. C., O’Campo, P., Anderson, J., Keller, J., \& Faden, R. (2000). Women living with HIV: Disclosure, violence, and social support. Journal of Urban Health, 77, 480-491.

Gielen, A. C., O'Campo, P., Faden, R. R., \& Eke, A. (1997). Women's disclosure of HIV status: Experiences of mistreatment and violence in an urban setting. Women and Health, 25, 19-31.

Gilbert, L., El-Bassel, N., Rajah, V., Foleno, A., Fontdevila, J., Frye, V., et al. (2000). The converging epidemics of moodaltering-drug use, HIV, HCV, and partner violence: A conundrum for methadone maintenance treatment. Mount Sinai Journal of Medicine, 67, 452-464.
Gilbert, L., El-Bassel, N., Rajah, V., Foleno, A., \& Frye, V. (2001). Linking drug related activities with experiences of partner violence: A focus group study of women in methadone treatment. Violence and Victims, 16, 517-536.

Gilbert, L., El-Bassel, N., Schilling, R. F., Wada, T., \& Bennet, B. (2000). Partner violence and sexual HIV risk behaviors among women in methadone treatment. AIDS and Behavior, 4, 261-269.

Gilbert, L., El-Bassel, N., Wu, E., \& Chang, M. (2007). Intimate partner violence and HIV risks: A longitudinal study of men on methadone. Journal of Urban Health, 84, 667-680.

Gil-Rivas, V., Fiorentine, R., Anglin, M. D., \& Taylor, E. (1997). Sexual and physical abuse: Do they compromise drug user treatment outcomes? Journal of Substance Abuse Treatment, 14, 351-358.

Go, V. F., Sethulakshmi, C. J., Bentley, M. E., Sivaram, S., Srikrishnan, A. K., Solomon, S., et al. (2003). When HIV-prevention messages and gender norms clash: The impact of domestic violence on women's HIV risk in slums of Chennai, India. AIDS and Behavior, 7, 263-272.

Hamburger, M. E., Moore, J., Koenig, L. J., Vlahov, D., Schoenbaum, E. E., Schuman, P., et al. (2004). Persistence of inconsistent condom use relation to abuse history and HIV serostatus. AIDS and Behavior, 8, 333-344.

Hashima, P. Y., \& Finkelhor, D. (1999). Violent victimization of youth versus adults in the national crime victimization survey. Journal of Interpersonal Violence, 14, 799-820.

Hogben, M., Gange, S. J., Watts, D. H., Robison, E., Young, M., Richardson, J., et al. (2001). The effect of sexual and physical violence on risky sexual behavior and STDs among a cohort of HIV seropositive women. AIDS and Behavior, 5, 353-362.

Hutton, H. E., Treisman, G. J., Hunt, W. R., Fishman, M., Kendig, N., Swetz, A., et al. (2001). HIV risk behaviors and their relationship to posttraumatic stress disorder among women prisoners. Psychiatric Services, 52, 508-513.

Inciardi, J. A., Pottieger, A. E., Forney, M. A., Chitwood, D. D., \& McBride, D. C. (1991). Prostitution, IV drug use, and sexfor-crack exchanges among serious delinquents: Risks for HIV infection. Criminology, 29, 221-235.

Irwin, K. L., Edlin, B. R., Wong, L., Faruque, S., McCoy, H. V., Word, C., et al. (1995). Urban rape survivors: Characteristics and prevalence of human immunodeficiency virus and other sexually transmitted infections. Obstetrics and Gynecology, 85, 330-336.

Jenny, C., Hooton, T., Bowers, A., Copass, M., Krieger, J., Hillier, S., et al. (1990). Sexually transmitted diseases in victims of rape. New England Journal of Medicine, 322, 713-716.

Johnson, B. D., Williams, T., Sanabria, H., \& Dei, K. (1989). Social impact of crack dealing in the inner city. National Institute on Drug Abuse Research Monograph, 95, 326-327.

Kalichman, S. C., Williams, E. A., Cherry, C., Belcher, L., \& Nachimson, D. (1998). Sexual coercion, domestic violence, and negotiating condom use among low-income African American women. Journal of Women's Health, 7, 371-378.

Kelly, J. A., \& Kalichman, S. C. (1995). Increased attention to human sexuality can improve HIV-AIDS prevention efforts: Key research issues and directions. Journal of Consulting and Clinical Psychology, 63, 907-918.

Kelly, J. A., Murphy, D. A., Bahr, G. R., Koob, J. J., Morgan, M. G., Kalichman, S. C., et al. (1993). Factors associated with severity of depression and high-risk sexual behavior among persons diagnosed with human immunodeficiency virus (HIV) Infection. Health Psychology, 12, 215-219.

Kessler, R., Sonnega, A., Bromet, E., Hughes, M., \& Nelson, C. (1995). Posttraumatic stress disorder in the National 
Comorbidity Survey. Archives of General Psychiatry, 52, 10481060.

Kilpatrick, D. G., Acierno, R., Resnick, H. S., Saunders, B. E., \& Best, C. L. (1997). A 2-year longitudinal analysis of the relationship between violent assault and substance use in women. Journal of Consulting and Clinical Psychology, 65, 834-837.

Kunins, H., Gilbert, L., Whyte, A., Meissner, P., \& Zachary, M. (2007). Substance abuse treatment staff perceptions of intimate partner victimization maong female clients. Journal of Psychoactive Drugs, 39, 251-258.

Leshner, A. (1998). Gender matters in drug abuse research. Rockville, MD: National Institute of Drug Abuse.

Lewis, C. F. (2005). Post-traumatic stress disorder in HIV positive incarcerated women. Journal of American Academy of Psychiatry and Law, 33, 455-464.

Lown, E. A., Winkler, K., Fullilove, R. E., \& Fullilove, M. T. (1995). Tossin' and tweakin': Women's consciousness in the crack culture. In A. Aauire (Ed.), Women and AIDS: Psychological perspectives. Thousand Oaks, CA: Sage.

Maman, S., Campbell, J., Sweat, M. D., \& Gielen, A. C. (2000). The intersections of HIV and violence: Directions for future research and interventions. Social Science \& Medicine, 50, 459-478.

McKay, J. R., Rutherford, M. J., Cacciola, J. S., KabasakalianMcKay, R., \& Alterman, A. (1996). Gender differences in the relapse experiences of cocaine patients. Journal of Nervous and Mental Disease, 184, 616-622.

Mcnutt, L.-A., Carlson, B. E., Persaud, M., \& Postmus, J. (2002). Cumulative abuse experiences, physical health and health behaviors. Annals of Epidemiology, 12, 123-130.

Medrano, M. A., Desmond, D. P., Zule, W. A., \& Hatch, J. P. (1999). Histories of childhood trauma and the effects of risky HIV behaviors in a sample of women drug users. American Journal of Alcohol Abuse, 25, 593-606.

Melchior, L., Huba, G., Brown, V., \& Slaughter, R. (1999). Evaluation of the effects of outreach to women with multiple vulnerabilities on entry into substance abuse treatment. Evaluation \& Program Planning, 22, 269-277.

Melendez, R. M., Hoffman, S., Exner, T., Leu, C. S., \& Ehrhardt, A. A. (2003). Intimate partner violence and safer sex negotiation effects of a gender-specific intervention. Archives of Sexual Behavior, 32, 499-511.

Miller, B. A., Downs, W. R., \& Testa, M. (1993). Interrelationships between victimization experiences and women's alcohol use. Journal of Studies on Alcohol, 11, 109-117.

Miller, N. S., Gold, M. S., \& Mahler, J. C. (1991). Violent behaviors associated with cocaine use: Possible pharmacological mechanisms. International Journal of the Addictions, 26, 1077-1088.

Mize, S. J. S., Robinson, B. E., Bockting, W. O., \& Scheltema, K. E. (2002). Meta-analysis of the effectiveness of HIV prevention interventions for women. AIDS Care, 14, 163-180.

Morrill, A., \& Ickovics, J. (1996). Surviving abuse and HIV risk: How women's experience of abuse shapes their heterosexual risk for HIV (abstract no. Tu.D.134). International AIDS Conference, 11, 254.

Morrow, S. L., \& Smith, M. L. (1995). Constructions of survival and coping by women who have survived childhood sexual abuse. Journal of Counseling Psychology, 42, 20-33.

New York City Department of Health and Mental Hygiene. (2007). NYC HIV/AIDS annual surveillance statistics, 2007. Retrieved June 15, 2009, from http://www.nyc.gov/html/doh/ downloads/pdf/ah/surveillance2006_tables_all.pdf

North, R. L., \& Rothenberg, K. H. (1993). Partner notification and the threat of domestic violence against women with HIV infection. New England Journal of Medicine, 329, 1194-1196.
O'Leary, A., \& Wingood, G. M. (2000). Interventions for sexually active heterosexual women. In J. L. Peterson \& R. J. DiClemente (Eds.), Handbook of HIV prevention (pp. 179-200). New York: Kluwer/Plenum.

Paone, D., Chavkin, W., Willets, I., Friedman, P., \& Des Jarlais, D. (1992). The impact of sexual abuse: Implications for drug treatment. Journal of Women's Health, 1, 149-153.

Raj, A., Santana, M. C., La Marche, A., Amaro, H., Cranston, K., \& Silverman, J. G. (2006). Perpetration of intimate partner violence associated with sexual risk behaviors among young adult men. American Journal of Public Health, 96, 1873-1878.

Raj, A., Silverman, J. G., \& Amaro, H. (2004). Abused women report greater male partner risk and gender-based risk for HIV: Findings from a community-based study with Hispanic women. AIDS Care, 16, 519-529.

Resnick, H., Kilpatrick, D., Dansky, B., Saunders, B., \& Best, C. (1993). Prevalence of civilian trauma and post-traumatic stress disorder in a representative national sample of women. Journal of Consulting and Clinical Psychology, 61, 984-991.

Rich, J. D., Dickinson, B. P., Macalino, G., Flanigan, T. P., Towe, C. W., Spaulding, A., et al. (1999). Prevalence and incidence of HIV among incarcerated and reincarcerated women in Rhode Island. Journal of Acquired Immune Deficiency Syndromes, 22, 161.

Rodriguez, M. A., Szkupinski Quiroga, S., \& Bauer, H. M. (1996). Breaking the silence: Battered women's perspective on medical care. Archives of Family Medicine, 5, 153-158.

Rothenberg, K. H., \& Paskey, S. J. (1995). The risk of domestic violence and women with HIV infection: Implications for partner notification, public policy and the law. American Journal of Public Health, 85, 1569-1575.

Saul, J., Moore, J., Murphy, S. T., \& Miller, L. C. (2004). Relationship violence and women's reactions to male- and femalecontrolled HIV prevention methods. AIDS and Behavior, 8, 207-214.

Schiff, M., El-Bassel, N., Engstrom, M., \& Gilbert, L. (2002). Psychological distress and intimate physical and sexual abuse among women in methadone maintenance treatment programs. Social Service Review, 76, 302-320.

Spunt, B. J., Goldstein, P. J., Bellucci, P. A., \& Miller, T. (1990). Race/ethnicity and gender differences in the drugs-violence relationship. Journal of Psychoactive Drugs, 22, 293303.

Sterk, C. E. (1999). Fast lives: Women who use crack cocaine. Philadelphia: Temple University Press.

Sterk, C. E., Dolan, K., \& Hatch, S. (1999). Epidemiological indicators and ethnographic realities of female cocaine use. Substance Use \& Misuse, 34, 2057-2072.

Straus, M. A., \& Gelles, R. (1990). How violent are American families? Estimates from the national family violence survey and other studies. In M. Straus \& Gelles, R. (Eds.), Physical violence in American families (pp. 95-112). New Brunswick, NJ: Transaction.

Teets, J. M. (1995). Childhood sexual trauma of chemically dependent women. Journal of Psychoactive Drugs, 27, 231-238.

Tjaden, P., \& Thoennes, V. (1998). Prevalence, incidence, and consequences of violence against women: Findings from the national violence against women survey. Washington, DC: United States Department of Justice, National Institutes of Health.

Tucker, J. S., Wenzel, S. L., Elliott, M. N., Marshall, G. N., \& Williamson, S. (2004). Interpersonal violence, substance use, HIV-related behavior and cognitions: A prospective study of impoverished women in Los Angeles County. AIDS and Behavior, 8, 463-474. 
Wathen, C. N., \& MacMillan, H. L. (2003). Interventions for violence against women: Scientific review. Journal of the American Medical Association, 289, 589-600.

Winfield, I., George, L. K., Swartz, M., \& Blazer, D. G. (1990). Sexual assault and psychiatric disorders among a community sample of women. American Journal of Psychiatry, 147, 335-341.

Wingood, G. M., \& DiClemente, R. J. (1997). The effects of an abusive primary partner on the condom use and sexual negotiation practices of African-American women. American Journal of Public Health, 87, 1016-1018.

Wingood, G. M., \& DiClemente, R. J. (1998). Partner influences and gender-related factors associated with noncondom use among young adult African American women. American Journal of Community Psychology, 26(1), 29-51.
World Health Organization. (1997). The female condom: A review. Geneva: Author.

Worth, D. (1989). Sexual decision-making and AIDS: Why condom promotion among vulnerable women is likely to fail. Studies on Family Planning, 20, 297-307.

Wu, E., El-Bassel, N., Witte, S. S., Gilbert, L., \& Chang, M. (2003). Intimate partner violence and HIV risk among urban minority women in primary health care settings. AIDS and Behavior, 7, 291-301.

Wyatt, G. E. (1991). Child sexual abuse and its effects on sexual functioning. Annual Review of Sex Research, 2, 249-266.

Wyatt, G. W., \& Newcomb, M. D. (1990). Internal and external mediators of women's sexual abuse in childhood. Journal of Consulting and Clinical Psychology, 58, 758-767. 